\title{
Do 7-year-old children understand social leverage?
}

Alejandro Sánchez-Amaro, Shona Duguid, Josep Call, and Michael Tomasello

\begin{tabular}{|l|l|}
\hline Date of deposit & 21072020 \\
\hline Document version & Author's accepted manuscript \\
\hline Access rights & $\begin{array}{l}\text { Copyright @ 2020 Elsevier Inc. All rights reserved. This work is } \\
\text { made available online in accordance with the publisher's policies. } \\
\text { This is the author created, accepted version manuscript following } \\
\text { peer review and may differ slightly from the final published } \\
\text { version. }\end{array}$ \\
\hline $\begin{array}{l}\text { Citation for } \\
\text { published version }\end{array}$ & $\begin{array}{l}\text { Sánchez-Amaro, A., Duguid, S., Call, J., \& Tomasello, M. (2020). } \\
\text { Do 7-year-old children understand social leverage? Journal of } \\
\text { Experimental Child Psychology, 199, [104963]. }\end{array}$ \\
\hline $\begin{array}{l}\text { Link to published } \\
\text { version }\end{array}$ & https://doi.org/10.1016/j.jecp.2020.104963 \\
\hline
\end{tabular}

Full metadata for this item is available in St Andrews Research

Repository at: https://research-repository.st-andrews.ac.uk/ 


\section{Introduction}

2 When people can unilaterally influence the outcomes of an interaction, they are in a position of power or, in other words, they have leverage over others. Leverage can be achieved in different ways. People can use physical force to punish others so that they conform to their will (Marquart, 1986) and they can also use third-parties as social alternatives to end previously disadvantageous interactions (Barclay, 2013). The access to alternatives such as different social partners, contracts or rewards, just like the possession of unique resources, can be a source of leverage because it creates asymmetries between interacting individuals. For example, an individual in possession of a unique resource could ask for higher prices than other suppliers because her goods or services are better than those of her competitors.

While the example mentioned above applies mainly to human adult interactions in which some basic economic understanding is required, social transactions of this nature also occur during childhood (e.g. children bargaining over collectable items such as trading cards). Recent studies have investigated the strategies that young children use to resolve conflicts of interest at the dyadic (Grueneisen \& Tomasello, 2017; Sánchez-Amaro, Duguid, Call, \& Tomasello, 2017, 2019) and the group level (Grueneisen \& Tomasello, 2019). However, little is known about whether children, who have minimal experience in market transactions, would use alternative options as leverage in social dilemmas.

Several studies have documented the development of children's abilities to coordinate towards mutual goals as well as to resolve conflicts of interest. After their second birthday children are already capable of actively coordinating their actions with peers to reach common goals (Brownell, Ramani, \& Zerwas, 2006) and to solve simple problems cooperatively (Ashley \& Tomasello, 1998). Later, between three and five years of age, children begin to demonstrate normative aspects of their collaborative activities, feeling committed to joint goals with their peers (Hamann, Warneken, Greenberg, \& Tomasello, 2011). At the same age, children are 
capable of solving collaborative tasks by considering the different roles that partners must adopt to solve a joint task (Fletcher, Warneken, \& Tomasello, 2012) and to plan division of labour in collaborative tasks (Warneken, 2018; Warneken, Steinwender, Hamann, \& Tomasello, 2014). From a very young age they also coordinate their decisions to collaborate in efficient ways (Wyman, Rakoczy, \& Tomasello, 2013) and by the age of four years old, they are capable of forgoing a less preferred but secure reward to obtain a mutually preferred one (Duguid, Wyman, Bullinger, Herfurth-Majstorovic, \& Tomasello, 2014).

When conflicts of interest arise, five-year old children develop strategies to resolve them. A conflict of interest occurs when there is no mutually beneficial solution, that is, children have different preferences for the outcome of an interaction. Several recent studies have focused on how children manage conflicts of interest in situations with the following structure: A pair of children are presented with an unequal reward distribution. The rewards are accessible for a limited amount of time and the high value reward is only accessible to the child that waits for her partner to act first. The conflict of interest arises because their preferences are not aligned: each child prefers the partner to act before them while the rewards are still accessible. Children have demonstrated the ability to establish cooperative strategies to overcome these conflicts of interest by taking turns to divide the rewards equally, even when this means that they receive no rewards on some turns, and communicate appropriately to coordinate their decisions (Grueneisen \& Tomasello, 2017; Melis, Grocke, Kalbitz, \& Tomasello, 2016; Sánchez-Amaro, Duguid, Call, \& Tomasello, 2019). A turn-taking strategy is most efficient when the interaction is predictable, e.g. repeated interactions with the same amounts of resources and it is easy for participants to keep track of previous interactions. When the distribution of rewards is unpredictable five-year-old children abandon cooperative strategies such as turn-taking in favour of competitive strategies to maximize their rewards (e.g. waiting for a partner to act before them when that results in better rewards for the passive individual; Sánchez-Amaro et al., 2017). Finally, around the same age, children are able to maintain depletable resources by 
generating their own rules and strategies such as distracting one another to prevent the collapse of a common pool resource (Koomen \& Herrmann, 2018).

Common to all of these situations is that children face a social dilemma and they must decide between acting cooperatively or selfishly (Dawes, 1980). On the one hand acting selfishly (e.g. waiting for the partner to act) is more beneficial than cooperating (e.g. acting before the partner). On the other hand, pairs can avoid the worst outcome (being the recipient of a selfish act) if they both cooperate and thus still obtain some rewards. In all these social dilemmas the interaction is always symmetrical. That is, despite children's goals not being aligned, both partners have the same options available to them and are thus likely to share the same strategies. However, little is known about the strategies that children would use to overcome conflicts of interest when their interaction is asymmetrical. For example, when only one child can access a secure alternative and thus can avoid participating in the social dilemma. That is, when one child is in a position of leverage.

Understanding how leverage (in the form of alternative options) can affect the decisions we make in social dilemmas has been experimentally studied in adult humans. In a study by Binmore, Shared, \& Sutton (1989) adult participants were asked to divide $\$ 7$ between themselves and an anonymous recipient. The recipient could accept the offer or reject it for both the participants. Participants also knew that the recipient had the option to exit the negotiation and obtain a $\$ 4$ alternative on his own. Under these conditions, participants offered recipients more than half the total amount (i.e. $\$ 4.50$ instead of $\$ 3.50$ each). This way participants ensured that recipients would accept their offer, avoiding a complete loss of the rewards. Evidence that adults understand others' positions of influence and adjust their decisions accordingly also comes from coordination games such as the Battle of Sexes (Cooper, DeJong, Forsythe, \& Ross, 1994; Cooper, DeJong, Forsythe, \& Ross, 1990). In an example of this two-player coordination game, two players (Player A and Player B) had the option to choose 600 
lottery tickets for themselves and 200 for the other or vice versa. However, if both players chose the 600 tickets for themselves, they would get no tickets. In addition, only Player A had the opportunity to opt out and obtain a secure reward of 300 tickets for each player. The experimenters found that players in position A chose the option that would provide them with the highest reward (600 tickets for themselves and 200 for the partner) on a majority of trials. In turn, players in position B anticipated this decision and chose 200 tickets for themselves. In other words, Player A influenced Player B's decision through the use of leverage. In these studies, adult participants played against anonymous partners and could not communicate.

Previous methods involving monetary rewards are hard to implement with young children. Instead, when testing children's strategies in social dilemmas it is preferable to present them with engaging scenarios in which they can interact and communicate as they would do in real life situations. Our study explores whether children can use a position of leverage when their personal preferences are not aligned. We build on a previous experiment (Sánchez-Amaro et al., 2017) in which five-year-old children were presented with a dyadic anti-coordination game, the Snowdrift (Sugden, 2004). In this game, each child would prefer their partner to be the one to cooperate (by pulling a rope) because cooperation provides more rewards for the child who waits (does not pull the rope). However, if both children wait for each other (i.e. mutual defection), they lose the opportunity to obtain any rewards. To implement this social dilemma, we presented children with an unequal reward distribution on two ends of a rotating tray. The rewards were placed at both ends but only the one end could be accessed directly by pulling a rope (henceforth the rope end), with the other end (the free end) moving towards the partner. In the critical condition, the preferred reward was placed on the free end of the tray so that the child could only obtain it by waiting for the partner to pull her rope. However, if both children waited too long for their partner to act, all rewards were lost. We found that children behaved strategically by pulling later when the preferred reward was not directly accessible to them. This task deviates from more traditional implementations of social dilemmas in that children were 
able to communicate, their decisions were inter-dependent (the actions of one child already determined what both children could obtain), they had limited time to act, and they were also familiar with each other (in the same class).

In the current study, we presented pairs of seven-year-old children with the same basic task: both individuals could either obtain one marble baited on the rope-end of the tray as reward when they pulled from their rope, or three marbles on the free end if they waited for their partner to pull. This created a conflict of interest, as both individuals would prefer their partner to pull before them. The difference with the previous study (Sánchez-Amaro et al., 2017) was that we added the possibility of using leverage. In this task one of the children could access an alternative, secure and exclusive reward (zero, two or four rewards, depending on the condition) in addition to the unequal reward distribution on the rotating tray accessible to both children. Henceforth, we call the child in possession of the alternative the subject and the child without an alternative the partner. The addition of potential leverage in the form of alternatives further differentiates our task from typical social dilemmas by creating asymmetries in the potential strategies for partners.

Subjects faced three conditions determined by the amount of rewards baited on the alternative. When there was no secure alternative (zero rewards; see Figure 1, scenario 1), both children had symmetrical options-they could only access the rotating tray- and thus there was no leverage. This re-created the snowdrift game presented to children in the previous study

122 (Sánchez-Amaro et al., 2017). When the alternative consisted of two rewards (Figure 1, scenario 1232 2), subjects could use it as leverage, operationalized as the possibility to access the alternative option instead of the rotating tray. This alternative is a greater reward than that for cooperation in the social dilemma, but less than they receive if the partner cooperated. Finally, when the alternative consisted of four secure rewards (Figure 1, scenario 3), subjects should always prefer the four rewards instead of accessing the rotating tray which either offered one or three 
rewards. An important aspect of the game is that choices between the rotating tray and the alternative are irreversible. Subjects only maintain their leverage while they have both options available, i.e. until they have made a decision. Thus, subjects should wait for their partners to pull for one reward before acting, otherwise they would lose the advantage conferred by their leverage. At the same time, partners should be more likely to pull for one reward before all rewards were removed given that subjects could easily access two rewards.

The introduction of the leverage in the form of an alternative option adds complexity to our previous task. In this scenario, children need to understand that their strategies might differ depending on the leverage level presented to the subject. In addition, depending on the situation children might need to inhibit their access to the secure alternative. In the previous study with the same rotating tray, we tested five-year olds (Sánchez-Amaro et al., 2017) but given the potential increase in complexity and task demands we decided to test a sample of older children (seven-year-olds) first.

In line with previous studies, we expected children to demonstrate strategies that successfully avoid mutual defection in the social dilemma, i.e. children waiting for each other until the experimenter removed the rewards (Sánchez-Amaro et al., 2017, 2019). We also expected children to be able to track the relative rewards available in each condition. Thus, we expect that the higher the value of the alternative the more likely they would be to forego the access to the rotating tray in favour of the alternative option. Importantly, we expected the seven-yearold children to understand the potential function of their leverage position. This is demonstrated by two measures (see also Figure 1 for a summary of the main predictions). Firstly, when the alternative consisted of two secure rewards, we expected subjects to wait for their partner to pull first. Secondly, we expected decrease in time waiting (both when acting as subject and as partner) with an increase in the value of the alternative option. For example, when the alternative consisted of four rewards (more than the reward available in the rotating tray) we 
expected children to access it directly and not wait for the other child. With regard to how children use communication, we expected children in both positions (as subject and as partner) to communicate in a similar manner when no child had leverage over the other. In contrast, when subjects had leverage over partners, we expected the latter to communicate more often: since subjects who hold the privileged position, partners need to persuade them to negotiate a better deal. Finally, we evaluated whether children would behave differently between sessions (the moment they changed their subject-partner roles). See Figure 1 for summary of the main hypotheses.

\begin{tabular}{|c|c|c|} 
access the rotating tray \\
after partner \\
Scenario 1
\end{tabular}

Figure 1: Representation of main hypothesis for subjects' and partners choices across the three different leverage levels (scenarios 1-3). If the rope is pulled by the subject the tray spins anticlockwise and one reward becomes accessible to the subject, three to the partner and vice versa if the partner pulls the rope and the tray spins clockwise. 


\section{Subjects}

177 We tested 20 pairs of 7 years and 0 months old to 7 years and 11 months old children (10 pairs 178 of boys and 10 pairs of girls; $\left.M_{a g e}=7 y-5 M-20 D, S D=4 M\right)$ in German schools within the Leipzig 179 city area. All participants were recruited from a database of children whose parents had 180 provided written consent to take part in child development and comparative studies. Pairs were 181 made up of children from the same school.

Apparatus

Pairs of children were presented with a rotating wooden tray positioned on top of a wooden platform, encased in a transparent plastic case (see Figure 2). In two of the corners of the case, on opposite sides, were transparent compartments approximately $3 \mathrm{~cm} \times 3 \mathrm{~cm}$ (henceforth referred to as alternative platforms). Children faced each other across the box and had access to the rotating tray and one of the alternative platforms. A transparent lid covered the surface of the box from the top to prevent children from accessing the rewards. On each side of the apparatus, transparent plastic doors blocked the openings to the rotating tray and to the alternative platform. Children could slide the door to the right to access the ropes connected to the roped (low value) end of the rotating tray. To access the free (high value) end of the rotating tray children had to wait for their partner to pull (Figure $2 b$ ). The alternative platform could be accessed directly by sliding the door to the left (Figure $2 \mathrm{~d}$ ). When a child slid the door to either side, a locking mechanism prevented the door from returning to its original position-this way children could only access one of the two options on a given trial. 
197

198

199

200

201

202

203

204

205

206

207

208

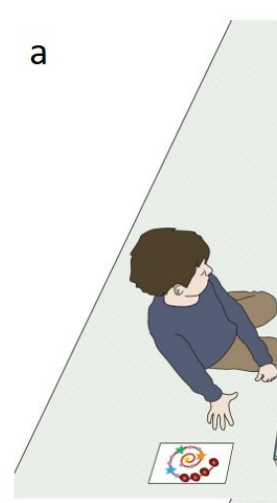

C
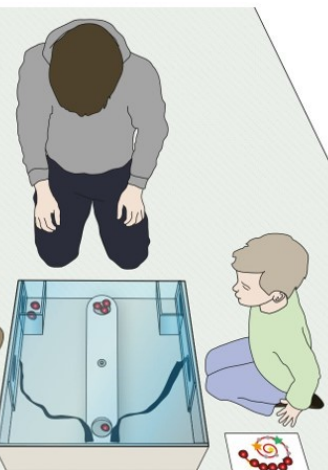

b
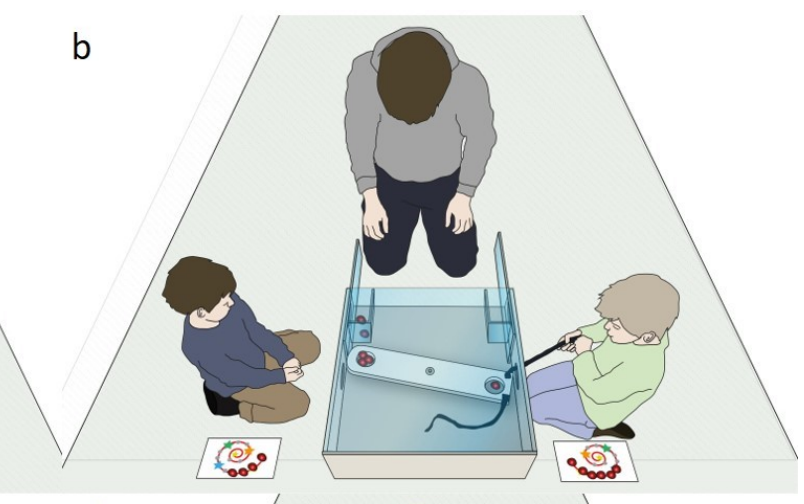

d
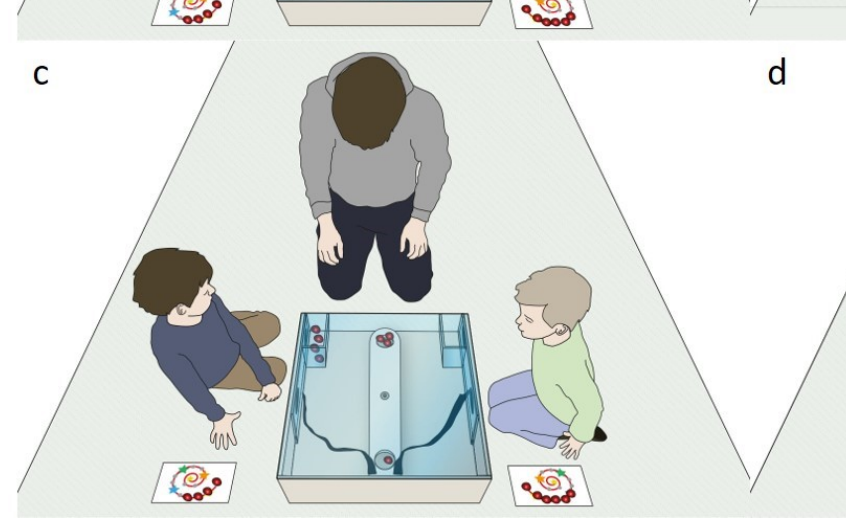

Figure 2: Representation of the apparatus. The subject is on the left side and has access to two rewards on the alternative (figures $a$ and $b$ ) or four rewards on the alternative (figures $c$ and $d$ ). In figure $b$ the subject access the unequal distribution while in figure $d$ the subject access the alternative.

\section{Design and procedure}

Before the test sessions, each child participated in three training phases.

\section{Training phase 1}

In the first training phase, pairs of children learned how to access the rewards from the rotating tray. After a period of warm-up in which an experimenter (henceforth E1) interacted with the children, E1 introduced children to the apparatus and to the second experimenter (henceforth E2). Children were told that E2 did not speak German; this way we minimized interactions between children and E2. This method has been successfully used on previous studies employing a similar methodology (Sánchez-Amaro et al., 2017; Sánchez-Amaro, Duguid, Call, \& Tomasello, 2018a). Children were asked to sit at opposite sides of the apparatus to play a game-children 
would change their sides after every training phase and test session. E1 told the children that the aim of the game was to obtain the maximum number of marbles from the wooden box and that E2 would control some parts of the apparatus (i.e. the blocking pegs and the positioning of the ropes). While E1 was referring to the rewards that children could get, E2 showed children a handful of small black wooden marbles. E1 told children that they could place their collected marbles inside the boxes beside them - these boxes were already prepared before the children came in. After that, E1 showed each child how to access the rotating tray by sliding the door to their right. Next, E2 baited the rotating tray with three marbles on the free end and one marble on the roped end of the tray. Each child performed one trial in which only the acting child had access to the roped end of the tray (i.e. the child pulling the rope obtained the rewards from that end while the other child obtained the rewards from the free end). After these two trials, children performed another two trials in which both of them had simultaneous access to their ropes and could decide which of them would pull. In all four trials the experimenters waited for children to make their decisions. If children hesitated to act, E1 encouraged them to pull from their ropes and collect the marbles. Once they finished the fourth trial, E1 informed children that they had obtained lots of marbles and that, in order to continue playing, one child should leave the room and wait for his or her turn.

\section{Training phase 2}

In the second training phase each child learned individually how to obtain rewards from the alternative platform and how to choose between the two options (alternative platform or rotating tray) to maximize the number of rewards. At the beginning of the second training phase E1 showed the child how to access their alternative platform by sliding the door to their left). E1 repeated to every child that they should try to obtain as many marbles as possible. In this training phase children were also allowed to retrieve the marbles from their partner's side, who was waiting outside the room. A child faced two types of trials differing in the number of rewards 
237 baited on the rotating tray and the alternative options. In one type of trial, the child found one

238 marble on each end of the rotating tray and four marbles on the child's alternative platform. To

239 succeed, the child had to access the alternative platform. In the second type of trial, the child

240 was presented with two marbles on each end of the rotating tray and two marbles on the child's

241 alternative platform. In these trials, the child had to access both ends of the rotating tray.

242 Each child was presented with a minimum of four trials separated in two blocks. In the first block,

243 a child experienced each type of trial once. If they failed to maximize the rewards on these two

244 trials, they were allowed to try again until they obtained the best outcomes. Eleven children

245 needed to repeat the first trial and one child needed to repeat the second trial (the maximum

246 number of extra trials for a child were two). This allowed children to learn the contingencies of

247 each type of trial. In the second block, each child experienced every type of trial once regardless

248 of the result. Seven children fail one trial in the second block ( 5 children repeated the first trial

249 and 2 children repeated the second trial).

Training Phase 3

251 In the third training phase the children played together again and experienced a no-conflict

252 situation where they could either access one reward from each side of the rotating tray or from

253 the alternative platform. E1 told children that they were ready to play together once again

254 because they had had already learned the functions of the apparatus. This phase had four trials:

255 two trials with one marble baited on each end of the rotating tray and two trials with one marble

256 baited on each alternative platform. The presentation order of the trials was randomized. During

257 this training phase, children did not receive help while making their decisions, but they were

258 told the reason why they failed when that occurred. In three pairs, one child failed one trial. 
After the third training phase, E1 told children that they were going to play the real game for better rewards. Concurrently, E2 showed children a handful of coloured glass marbles, the new type of rewards they were going to collect.

Afterwards, E1 invited children to follow her to another side of the room. E1 presented each child with a laminated paper sheet. Each paper sheet contained a spiral made up of 40 connected dots. Every five dots there was star-shaped. The size of the stars increased towards the centre of the spiral. E1 told children that they should collect as many marbles as possible and place each marble on a spiral dot-starting from the outer dots and filling them towards the centre. For each star they filled, they would obtain a surprise at the end of the game. The spirals were created in a way that it was impossible for any child to reach the last star (i.e. there were more dots than glass marbles). While children were informed how to use the laminated sheet, E2 removed the boxes containing the wooden marbles that children had obtained during their training. After children got their laminated sheets, they returned to their positions in front of the box. At that moment, E1 told them that she had to leave the room. Once they were alone with $E 2$, the first session began.

Each pair of children participated in two test sessions. For the first session, children were randomly assigned the role of subject or partner. They changed roles between sessions-half of children played as subject in session one and the other half as subject in session two. Pairs of Afterwards, E1 left the room again and children completed their second test session.

Both children had access to the rewards baited on both ends of the rotating tray. However, only subjects could get rewards baited on their alternative platform. During test trials, the roped end of the rotating tray contained one glass marble while the free end contained three. The subjects' alternative platform could contain zero, two or four marbles (henceforth leverage levels zero, 

presentation order was randomized within sessions. Thus, children experienced the same amount of trials per leverage condition (two trials) on each session (except for one pair in which the leverage level two was presented three times and the leverage level four was presented only once due to an error). For half of the pairs the subjects' alternative was always located on the right platform, and for the other half it was located on the left platform.

The test trial started when the experimenter simultaneously removed both pegs blocking the sliding doors. A trial lasted from the moment the experimenter removed the pegs until both children accessed the apparatus and obtained the rewards, or 15 seconds if one or both children did not act. After that time, the experimenter removed all the remaining rewards and ended the trial. Following previous methods (Sánchez-Amaro et al., 2017, 2019), we did not inform children about the time they had to access the rewards.

\section{Coding}

We investigated whether children used strategies to maximise their rewards; specifically, whether they used their position of leverage strategically (i.e. whether subjects obtain the three rewards more often than partners and whether subjects wait for partners to act; see Table 1). We were also interested in whether the conflict of interest would lead to a complete breakdown of coordination and some children would receive no rewards. To do this we focused on their actions and verbal communication during test trials.

We coded three aspects of the participants' actions: rewards distribution, choices made and their timing (latencies). We calculated the percentage of trials in which both children obtained rewards, only one child obtained rewards and when both children failed to obtain anything. We also recorded their choices. Within a trial, children had four different options: 1) access the 
E2 removed the blocking pegs (trial starts) until children either opened their access to the rotating tray or to their alternative platform and 2) from the time they access the rotating tray until they pulled their rope. We scored the same latency measure for subjects and partners using specialized video-coding software (Mangold Interact $\mathrm{GmbH}$ ).

314 To code the verbal communication, we adapted a previous coding scheme used to study children's communication in a similar conflict of interest (see Sánchez-Amaro et al., 2019). As a first step we transcribed all verbal communication and pointing gestures that occurred from the moment E2 showed the rewards to the children (just before the rewards were baited on the box) until E2 showed the rewards to the children in a subsequent trial, or after E2 stood up to indicate the end of the session. We divided trials in two-time phases: from when E2 showed the rewards until the last child emptied the box (trial phase) and from the moment both children emptied the box until the next trial started (inter-trial-interval). As a second step communicative acts were assigned to categories that could indicate how children were solving the conflict of interest:

i) Informative communication: acts aimed at informing child's current or impending actions or intentions (e.g. "I am going to pull").

ii) Imperative communication: use of deontic verbs to guide others decisions (e.g. "you must pull").

iii) Protests: statements of disapproval or objection about another child's actions or intentions (e.g. "no, I also wanted").

iv) From the subjects' perspective we coded if children referred to their own leverage as part of their arguments (henceforth reference to leverage: e.g. "I am going to wait because I have this [indicating the leverage]" or "now I will access here [the leverage]"). From the partners' perspective we also coded their references to the 
subjects' leverage (e.g. "you should pull here [as opposed to accessing the leverage] this time").

v) We coded whether children used arguments to refer to future or past actions (henceforth turn-taking communication: e.g. "next time you pull" or "next time it is my turn because.."). These types of arguments are expected if children engage in turn-taking strategies for cooperation.

For each child (either as subject or as partner) and each trial phase we coded whether they communicated or not in any of the ways described above. Thus, multiple categories could occur for each child within a trial phase. In total, each communicative act could appear four times within a trial.

In addition to verbal communication, we recorded points to three different locations: 1) the rotating tray, 2) the alternative platform (i.e. the leverage) and 3) other task-related points (i.e. pointing at the reward sheet, at the experimenter or at the other child).

\section{Statistical analysis}

All the analyses were run using R statistics (version 3.1.1). Generalized linear mixed models were used to investigate children choices (to either access the alternative platform or the rotating tray; Model 1) and communicative acts (whether leverage level, included as a 3-level factor, and trial phase influenced subjects' and partners' communicative acts (Model 4) (Baayen, Davidson, \& Bates, 2008). To implement these models we used the "Ime4" package (Bates, 2010). To obtain the P values for the individual fixed effects we conducted likelihood-ratio tests. We assessed the stability of these models by comparing the estimates derived from models based on all data with those obtained from models with the levels of the random effects excluded one at a time. The models were stable. 
Mixed-effects Cox proportional hazard models (Models 2 and 3) were used to analyse subjects and partners latencies to act. For this purpose we used the "coxme" function from the "coxme" package (Therneau, 2012). This approach allows to analyse the variability attributable to the independent variables while controlling for right-censored data (i.e. when children did not act after the 15 seconds limit established by the experimenter). The results of the coxme models are reported as hazard ratios (HR). An HR greater than one indicates an increased hazard of acting (either opening the door in model 2 , or pulling the rope in model 3) while an HR smaller than 1 indicated a decreased hazard of acting. In addition, we conducted likelihood-ratio tests to obtain the $P$ values for the individual fixed effects.

To rule out collinearity we checked the variance inflation factors (VIF) for the GLMM and the coxme models. All VIF values were closer to 1 .

Reliability

The inter-observer reliability based on $20 \%$ of the data was excellent. Cohen Kappa's were calculated to assess the reliability of children's choices from the left and the right side of the apparatus. Pearson $\mathrm{R}^{2}$ were calculated to assess the reliability of latencies to open the doors and pull the ropes from both side of the apparatus. When children sat on the right side: latency to open the door (Cohen Kappa $=1$, Pearson $\mathrm{R}^{2}=0.99$ ) and latency to pull from the rope (Cohen Kappa $=1$, Pearson $R^{2}=0.99$ ). When children sat on the left side: latency to open the door (Cohen Kappa $=0.96(2 \%$ of data mismatch between observers $)$, Pearson $\left.\mathrm{R}^{2}=0.97\right)$ and latency to pull from the rope (Cohen Kappa $=0.96\left(2 \%\right.$ of data mismatch between observers), Pearson $\mathrm{R}^{2}=$ 0.99). 
Based on $20 \%$ of the data, the inter-observer reliability was excellent. Cohen Kappa's were calculated to assess the reliability of communication coding and whether observers interpreted those communicative acts as informative acts of communication or not: occurrence of communication (Cohen Kappa $=1$ ) and occurrence of informative acts (Cohen Kappa $=0.75$ ). We only looked at informative acts of communication because we could analyse their impact separately. Informative acts of communication accounted for $57 \%$ of communication (each act appearing a maximum of four times per trial).

\section{Results}

Both children obtained rewards in a majority of trials ( $87.1 \%, 209$ of the 240 trials), only one child obtained rewards in $5.8 \%$ of trials ( 14 of the 240 trials) and no children obtained rewards in $7.1 \%$ of trials (17 of the 240 trials). We found that subjects tried to maximize their rewards. This is reflected in their increasing likelihood to choose the alternative option with increasing reward value (GLMM: $\chi^{2}=74.35, \mathrm{df}=3, p<0.001, \mathrm{~N}=240$; Figure 3 ). When subjects had no alternative option, they accessed the rotating tray in most trials $(90 \%, 72$ of the 80 trials; only 6 children ever accessed the alternative). In contrast, when their alternative option consisted of four rewards - and thus the best outcome available - they accessed the rotating tray in only $5 \%$ of trials ( 4 of the 79 trials, 39 children accessed the alternative at least once). Interestingly, subjects chose to access the rotating tray in $42 \%$ of trials ( 34 of the 81 trials) when their leverage consisted of two marbles ( 28 children accessed the alternative at least once), significantly more often than when their leverage consisted of four marbles (GLMM: $\chi^{2}=68.42, \mathrm{df}=2, p<0.001, \mathrm{~N}$ = 240; see Table 1). In other words, in a substantial amount of trials children were willing to refuse two secure rewards to access the ropes connected to the rotating tray. In addition, we found that children who participated as subjects in the second session (after being partners) were less willing to access the rotating tray (in $40 \%$ of trials, 48 of the 120 trials) rather than the 


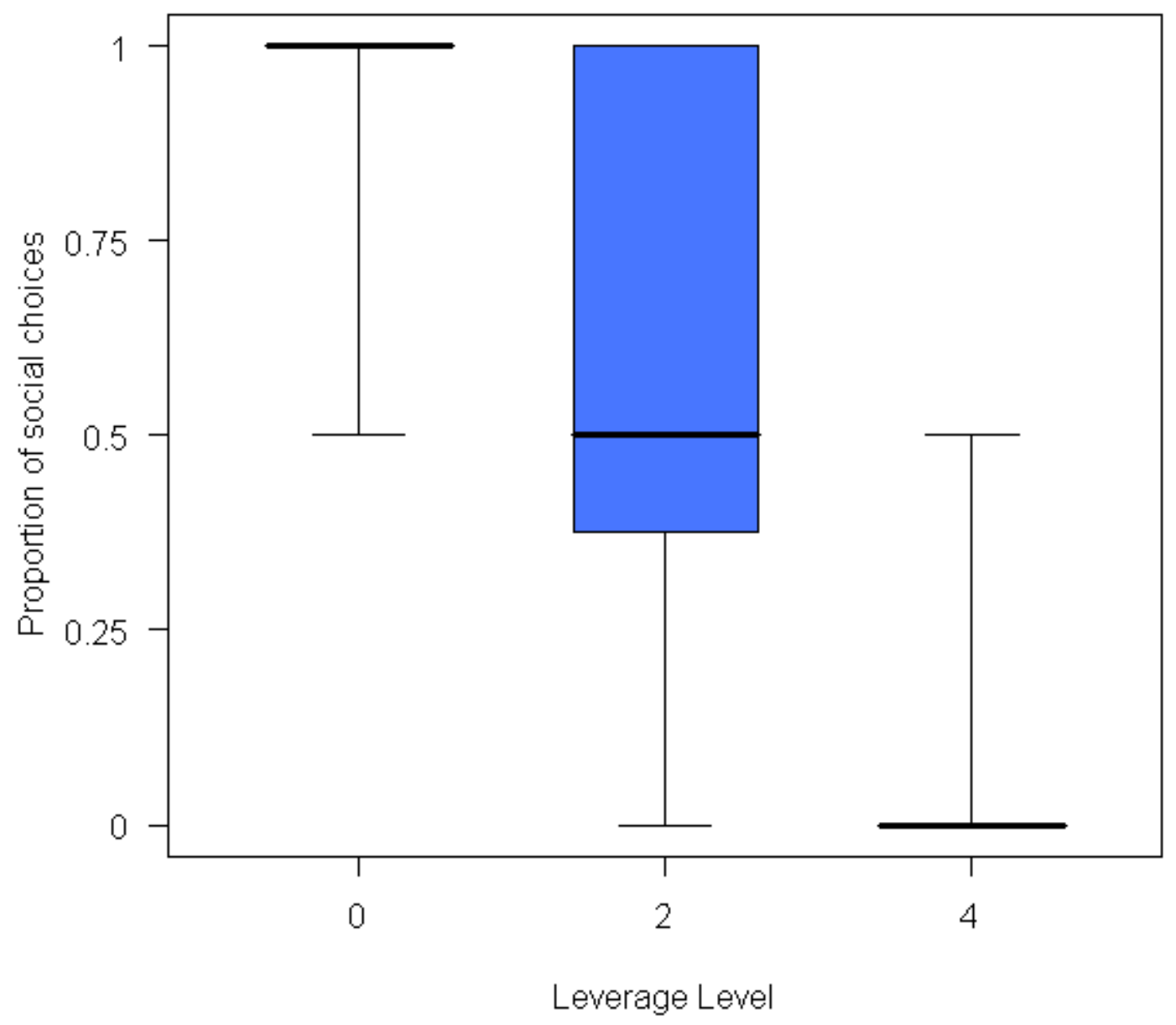

408

409 Figure 3: Proportion of social choices as a function of the level of leverage. The box-plots represent the median (thick line) and interquartile range of the proportion of times that each

411 subject accessed the social choice (i.e. the unequal reward distribution). The dotted line 412 represents the model fitted values.

413 To use the leverage effectively, children in the role of subjects should access the rotating tray 414 after partners had already pulled from their ropes. Once both individuals only had access to their ropes, they were in an equal position to obtain the best reward. Of the trials in which subjects 
416 chose the social option rather than two secure rewards ( $42 \%$ of trials, 34 of the 81 trials), they

417 made the most of their leverage, by waiting for the partner to pull before they access the social

418 option, in $38 \%$ of those trials (13 of the 34 trials). In other words, subjects used their leverage

419 strategically in $16 \%$ of the total trials (13 of the 81 trials). Subjects were able to maximize their

420 rewards (i.e. obtain the three rewards from the free end of the rotating tray; see Table 1).

421 Table 1: Number and percentage of trials in which subjects access the alternative, subjects pull

422 first and partners pull first. Also shown is the percentage of trials in which partners pulled before

423 the subjects acted and the percentage of trials in which both refused to pull after or before

424 accessing the rotating tray. Notice that the percentage of trials in which the partner pulls before

425 the subject acts is only relevant when the leverage level is 2 , and is a subset of trials in which

426 the partner pulls first.

\begin{tabular}{|c|c|c|c|c|c|c|}
\hline \multirow[b]{3}{*}{$\begin{array}{c}\text { Leverage } \\
\text { level }\end{array}$} & \multicolumn{2}{|c|}{ Subject } & \multicolumn{2}{|c|}{ Partner } & \multicolumn{2}{|c|}{ Subject and partner } \\
\hline & no pull & pull & & & no pull & no act/no pull \\
\hline & access alternative & First & First & $\begin{array}{c}\text { before } \\
\text { subject acts* }\end{array}$ & $\begin{array}{l}\text { after accessing } \\
\text { the rotating } \\
\text { tray }\end{array}$ & $\begin{array}{l}\text { before accessing } \\
\text { the rotating tray }\end{array}$ \\
\hline Leverage 0 & $6 / 80$ trials $(7.5 \%)$ & $\begin{array}{c}41 / 80 \text { trials } \\
(51.25 \%)\end{array}$ & $\begin{array}{c}24 / 80 \text { trials } \\
(30 \%)\end{array}$ & NA & $\begin{array}{c}7 / 80 \text { trials } \\
(8.75 \%)\end{array}$ & $2 / 80$ trials $(2.5 \%)$ \\
\hline Leverage 2 & $44 / 81$ trials $(54.3 \%)$ & $\begin{array}{c}11 / 81 \text { trials } \\
(13.6 \%)\end{array}$ & $\begin{array}{c}21 / 81 \text { trials } \\
(25.9 \%)\end{array}$ & $\begin{array}{c}13 / 81 \text { trials } \\
(16 \%)\end{array}$ & $\begin{array}{c}2 / 81 \text { trials } \\
(2.5 \%)\end{array}$ & $3 / 81$ trials $(3.7 \%)$ \\
\hline Leverage 4 & $74 / 79$ trials (93.7\%) & $\begin{array}{c}2 / 79 \text { trials } \\
(2.5 \%)\end{array}$ & $\begin{array}{c}2 / 79 \text { trials } \\
(2.5 \%)\end{array}$ & NA & & $1 / 79$ trials $(1.3 \%)$ \\
\hline
\end{tabular}

428 When we inspected the latencies to act (for the subject this was open the sliding door and

429 choosing one option; for the partner this was pulling the rope connected to the rotating tray), 
we found that both subject (coxme, $\chi^{2}=26.59, \mathrm{df}=2, p<0.001, \mathrm{~N}=240$; Figure $\mathrm{S} 1$ ) and partner

431 (coxme, $\chi^{2}=8.84, \mathrm{df}=2, \mathrm{p}=0.012, \mathrm{~N}=240$; Figure $\mathrm{S} 2$ ) latencies were affected by the subjects' leverage. Pairwise comparisons indicated that subjects waited to act a similar amount of time when they had no leverage and when their leverage consisted of two glass marbles (coxme,HR $=1.16, p=0.41, \mathrm{~N}=240$ ). That is, when they could not access the best rewards on their own, children in the role of subjects waited longer for their partners to act. In contrast, when subjects could access four glass marbles on the alternative platform, they acted significantly faster compared to when they had two (coxme, $\mathrm{HR}=2.15, \mathrm{p}<0.001, \mathrm{~N}=240$ ) or no alternative rewards (coxme, $\mathrm{HR}=2.49, \mathrm{p}<0.001, \mathrm{~N}=240$ ). Children in the role of partner also waited to act a similar amount of time when both children had no leverage and when the subject could access two alternative rewards (coxme, $\mathrm{HR}=0.94, \mathrm{p}=0.84, \mathrm{~N}=240$ ). Children in the role of partner also acted significantly faster when the subject could access four instead of two glass marbles from her alternative platform (coxme, $\mathrm{HR}=0.32, \mathrm{p}=0.0161, \mathrm{~N}=240$ ). This is especially interesting from the partners' perspective as it suggests that children did not need to have the leverage themselves to understand its role during the interaction. In other words, children in the role of partner inferred what subjects would choose based on the subjects' leverage position before subjects had made a decision. We found no significant differences in latencies (either as subject or as partner) between sessions, so changes in partner role did not seem to have an effect (see ESM).

Children did not communicate more often during the dilemma phase than during the inter-trialinterval phases regardless of their role and or the leverage presented on the subject's alternative platform (GLMM: $\chi^{2}=6.43, \mathrm{df}=6, p=0.37, \mathrm{~N}=240$; see Table S1). Additionally, we found no statistical differences in children informative acts of communication between trial phases, role and or condition presented (GLMM: $\chi^{2}=4.84, \mathrm{df}=6, p=0.56, \mathrm{~N}=240$ ). Other categories of communication such as imperatives, protest, references to leverage and turn-taking occurred 
roles and leverage levels. Partners generally protested more than subjects (see Table S4). This

457 might be explained by the fact that subjects obtained more rewards than partners in a majority of trials.

We found that children pointed in a minority of trials $(17 \% ; N=40)$. In total, children performed the partner role (subjects producing $61 \%$ of points). Points towards the leverage accounted for $33 \%$ of trials while pointing gestures towards the rotating tray accounted for $24 \%$ of trials. However, a majority of pointing gestures (42\%) were categorized as general pointing acts. Interestingly, $73 \%$ of communicative acts (16 of 22 ) containing references to the alternative option -the source of leverage-occurred in conjunction with pointing acts towards the rotating tray or/and the leverage.

\section{Discussion}

When presented with an asymmetrical social dilemma, we found some evidence that sevenyear-old children used access to alternative rewards as leverage to maximize their own benefits.

We expected that children would use their leverage strategically by waiting for their partners to act before them. We found that in over $15 \%$ of trials children initially in the position of leverage maintained it by waiting to make their decisions until their partners had already decided to pull

473 for the lower reward. We also expected children to wait less with increasing amounts in the 474 alternative. We found that children in the role of subject did wait less when the alternative contained four rewards but they did not differentiate between two or zero rewards on the alternative, presumably because in both cases they could maximise their own rewards by

477 waiting for the partner, regardless of leverage. Similarly, children in the role of partner also waited less when the subjects had an alternative of four rewards as compared to zero or two rewards, but did not differentiate between two or zero rewards. It is conceivable that when 
their own rewards by waiting. This is especially interesting from the partners' perspective

482 because it suggests that children could anticipate the effect of alternative options on the actions 483 of others.

In addition, we found that children playing the subject role accessed the alternative more often (regardless of the leverage level presented) in the second session (i.e. when they already had experience as a partner). However, the children's decisions were not entirely consistent with a thorough understanding of their leverage position. They still often accessed either their alternative option or the rotating tray before their partner had made a decision. In addition, we found that children rarely referred to the leverage. Perhaps this is due to the asymmetric nature of the interaction. They may have found little room for negotiation when their potential options were unequal. However, in those cases in which children verbally referred to the alternative option, they accompanied their utterances with pointing gestures towards the apparatus, most likely as a way to emphasize the source of leverage to their partner. In addition, we did observe that children in the role of partner (the disadvantaged position) generally protested more than their counterparts. In what follows, we discuss a number of possible reasons that could explain these results.

A simple account of our results could be that the task was too cognitively demanding for children to be able to use their leverage efficiently. They did not understand that, depending on the available alternatives, they could obtain more rewards by waiting for their partners to act. We find this explanation implausible as children passed several training phases before they entered the test phase, demonstrating that they understood the required actions to maximize rewards. In addition, the latencies to access the rewards as well as the pattern of decisions suggest that they partially understood the conflict of interest presented in the game. Moreover, previous studies using the same rotating tray suggested that five-year-old children understood a simpler version of the social dilemma (Sánchez-Amaro et al., 2017). 
507 not understand the social dilemma, but saw it as a non-social economic game. In this case we would expect children to choose the highest value reward they could access. Children in the subject role were equally likely to choose two rewards from the alternative option or the rotating tray (which would provide one reward if they pulled alone). From an economic perspective, this result makes sense as both options would lead to an average of two rewards over repeated trials. However, the timing of the children's actions, in this study as well as previous studies presenting children with similar social dilemmas (Sánchez-Amaro et al., 2017, 2019), are inconsistent with a non-social interpretation of their decision making. In addition, children were more likely to exploit the alternative option after having played as partner first, perhaps in an attempt to restore inequity between participants since partners usually got less rewards. Although, it is also possible that children playing as subjects in the second session already had more experienced and thus tried to maximize their rewards more often by accessing the alternative. Therefore, we suggest that children took into account the presence of the other child and her potential decisions, thus, interpreting the game as a social dilemma in which personal decisions directly affected each other's outcomes.

Nonetheless, children are clearly not using the position of leverage consistently or to its full potential. We suggest two potential drivers of their decisions. The first is that seven-year-olds may be willing to take the risk (i.e. choose the rotating tray instead of the two secure rewards) to get the higher reward, regardless of their strategic advantage with the leverage. Previous studies suggest that young children tend to be more risk-prone than adults in a number of 527 different scenarios (Boyer, 2006; Harbaugh, Krause, \& Vesterlund, 2002; Paulsen, Platt, Huettel, $528 \&$ Brannon, 2011). This is in line with our finding from the current study that children accessed 529 the rotating tray, the risky option, in almost half of the trials when they had two as an alternative option (i.e. they had leverage). However, these studies usually present children with non-social gambling situations whereas, in our study the risk was a social one (e.g. the partner could also 
decide to wait for them to pull). Adults are found to be more risk averse in social than non-social

533 contexts (Bohnet \& Zeckhauser, 2004) so we would need further studies to test this hypothesis

534 with children.

535 A second explanation for the failure to use leverage is that children were trying to establish cooperative solutions to the unequal reward distribution and thereby restore equity between players (Warneken, 2018). From early on in ontogeny, children are willing to distribute the benefits generated through collaboration (Ulber, Hamann, \& Tomasello, 2015; Warneken, Lohse, Melis, \& Tomasello, 2011). One common way to distribute rewards over time is to engage in turn-taking, a strategy that children and adult humans use in a variety of social dilemmas to stabilize cooperation (Grueneisen \& Tomasello, 2017; Helbing, Schönhof, Stark, \& Hołyst, 2005; Melis et al., 2016; Sánchez-Amaro et al., 2019). In our task children did occasionally encourage their partners to engage in turn-taking strategies. However, a turn-taking strategy in this scenario would have been challenging due to the asymmetrical and variable options children faced across trials (see also Sánchez-Amaro et al., 2017). Instead, children may have found alternative strategies to reduce inequity between subject and partner payoffs. For example, when subjects had no leverage (their alternative option was empty) they pulled so their partner received the higher reward in the majority of trials (67\%). This is also the condition in which we see the most protest from partners and could be one way of compensating for conditions when the subject usually gains more rewards. Consistent with the notion of restoring equity, we found that children acting as subjects second (in session two) were more likely to exploit the leverage,

552 perhaps as a strategy to obtain more resources than they had obtained as partners. Studies 553 suggest that an aversion towards disadvantageous inequality starts to develop early in ontogeny 554 (LoBue, Nishida, Chiong, DeLoache, \& Haidt, 2011; McAuliffe, Blake, Kim, Wrangham, \& 555 Warneken, 2013) followed by an aversion towards advantageous inequity around age 7-8 (Blake et al., 2015; Blake \& McAuliffe, 2011). Furthermore, it is possible that some children let others obtain the best rewards to prevent reputational damage since both children were from the same 
559 2015). Future studies could then assess whether the degree of familiarity plays a major role in 560 children decision-making strategies in social dilemmas.

561

562

\section{Conclusions}

These results advance our understanding of how children overcome conflicts of interest with peers by introducing a leverage component in a social dilemma. In that sense, this study deviates from previous work showing how younger children coordinate actions when the potential outcomes are symmetric and thus easier to predict (Grueneisen \& Tomasello, 2017; Melis et al., 2016). However, the current study was a demanding task for seven-year-old as illustrated by their resulting actions. For the future, the introduction of leverage in different ways may help us to understand children decision-making in these types of social conflicts from an earlier age. For example, qualitative instead of quantitative differences between rewards may reduce the computational load due to the number of items presented on a given trial. Furthermore, as mentioned earlier, leverage can be instantiated in diverse ways including access to alternative partners (e.g. a child that can access one game others cannot). In this regard, it would be interesting to explore how children would make use of social leverage when alternatives are social partners with distinct qualities and characteristics.

The current task also required children to wait for their partner to act before them to maximize their chances of obtaining the best rewards. Thus, children with greater delayed gratification skills would have had an advantage. Previous work has assessed the relationship between executive inhibitory control and cooperative behaviour (Ciairano, Visu-Petra, \& Settanni, 2007; Giannotta, Burk, \& Ciairano, 2011). Children with higher degree of inhibitory control were better co-operators in a puzzle task. Future studies could investigate the relationships between inhibitory control and decision-making in the context of social dilemmas. Finally, the resolution of social conflicts through the use of coordination games is tightly linked with the use of Theory 

assess the role of Theory of Mind abilities in our task, children could observe and respond to the actions of their partner and were also free to communicate about future actions. Evidence from studies preventing children from communicating with each other has shown that after their sixth birthday, they are able to form first and second-order false-belief reasoning to coordinate actions when their interests are aligned (Grueneisen, Wyman, \& Tomasello, 2015; Raijmakers, Mandell, van Es, \& Counihan, 2014). Applying similar methods to coordination games with leverage could offer novel ways to explore the role of ToM abilities on coordination over conflict situations. In sum, we found that by seven years of age, children seem to understand the potential role that individual alternatives play in a social dilemma, but they do not fully use it to their own advantage. Our findings could be the result of a trade-off between maximizing rewards, while maintaining long-term collaboration in complex scenarios where strategies such as turn-taking are hard to implement.

597 


\section{References}

609

610

611

612

613

614

615

616

617

618

619

620

621

622

623

624

625

626

627

Anderson, P. (2002). Assessment and development of executive function (EF) during childhood. Child Neuropsychology, 8(2), 71-82.

Ashley, J., \& Tomasello, M. (1998). Cooperative problem-solving and teaching in preschoolers. Social Development, 7(2), 143-163.

Baayen, R. H., Davidson, D. J., \& Bates, D. M. (2008). Mixed-effects modeling with crossed random effects for subjects and items. Journal of Memory and Language, 59(4), 390-412.

Barclay, P. (2013). Strategies for cooperation in biological markets, especially for humans. Evolution and Human Behavior, 34(3), 164-175.

Bates, D. M. (2010). Ime4: Mixed-effects modeling with R. Berlin.

Binmore, K., Shared, A., \& Sutton, J. (1989). An outside option experiment. The Quarterly Journal of Economics, 104(4), 753-770.

Blake, P R, McAuliffe, K., Corbit, J., Callaghan, T. C., Barry, O., Bowie, A., ... Vongsachang, H. (2015). The ontogeny of fairness in seven societies. Nature, 528(7581), 258.

Blake, Peter R, \& McAuliffe, K. (2011). "I had so much it didn't seem fair": Eight-year-olds reject two forms of inequity. Cognition, 120(2), 215-224.

Bohnet, I., \& Zeckhauser, R. (2004). Trust, risk and betrayal. Journal of Economic Behavior \& Organization, 55(4), 467-484.

Boyer, T. W. (2006). The development of risk-taking: A multi-perspective review. Developmental Review, 26(3), 291-345. 
Brownell, C. A., Ramani, G. B., \& Zerwas, S. (2006). Becoming a social partner with peers: Cooperation and social understanding in one-and two-year-olds. Child Development, $77(4), 803-821$.

Ciairano, S., Visu-Petra, L., \& Settanni, M. (2007). Executive inhibitory control and cooperative behavior during early school years: A follow-up study. Journal of Abnormal Child Psychology, 35(3), 335-345.

Cooper, R., DeJong, D. V, Forsythe, R., \& Ross, T. W. (1994). Alternative Institutions for Resolving Coordination Problems: Experimental Evidence on Forward Induction and Preplaycommunication. In Problems of coordination in economic activity (pp. 129-146). Springer.

Cooper, R. W., DeJong, D. V, Forsythe, R., \& Ross, T. W. (1990). Selection criteria in coordination games: Some experimental results. The American Economic Review, 80(1), 218-233.

Dawes, R. M. (1980). Social dilemmas. Annual Review of Psychology, 31(1), 169-193.

Duguid, S., Wyman, E., Bullinger, A. F., Herfurth-Majstorovic, K., \& Tomasello, M. (2014). Coordination strategies of chimpanzees and human children in a Stag Hunt game. Proceedings of the Royal Society of London B: Biological Sciences, 281(1796), 20141973.

Engelmann, J. M., Over, H., Herrmann, E., \& Tomasello, M. (2013). Young children care more about their reputation with ingroup members and potential reciprocators. Developmental Science, 16(6), 952-958.

Fletcher, G. E., Warneken, F., \& Tomasello, M. (2012). Differences in cognitive processes underlying the collaborative activities of children and chimpanzees. Cognitive Development, 27(2), 136-153.

Fujii, T., Takagishi, H., Koizumi, M., \& Okada, H. (2015). The effect of direct and indirect 

monitoring on generosity among preschoolers. Scientific Reports, 5, 9025.

653

654

655

656

Giannotta, F., Burk, W. J., \& Ciairano, S. (2011). The role of inhibitory control in children's cooperative behaviors during a structured puzzle task. Journal of Experimental Child Psychology, 110(3), 287-298.

Grueneisen, S., \& Tomasello, M. (2017). Children coordinate in a recurrent social dilemma by taking turns and along dominance asymmetries. Developmental Psychology, 53(2), 265.

Grueneisen, S., \& Tomasello, M. (2019). Children use rules to coordinate in a social dilemma. Journal of Experimental Child Psychology, 179, 362-374.

Grueneisen, S., Wyman, E., \& Tomasello, M. (2015). "I know you don't know I know...” Children use second-order false-belief reasoning for peer coordination. Child Development, 86(1), 287-293.

Hamann, K., Warneken, F., Greenberg, J. R., \& Tomasello, M. (2011). Collaboration encourages equal sharing in children but not in chimpanzees. Nature, 476(7360), 328.

Harbaugh, W. T., Krause, K., \& Vesterlund, L. (2002). Risk attitudes of children and adults: Choices over small and large probability gains and losses. Experimental Economics, 5(1), $53-84$.

Hedden, T., \& Zhang, J. (2002). What do you think I think you think?: Strategic reasoning in matrix games. Cognition, 85(1), 1-36.

Helbing, D., Schönhof, M., Stark, H.-U., \& Hołyst, J. A. (2005). How individuals learn to take turns: Emergence of alternating cooperation in a congestion game and the prisoner's dilemma. Advances in Complex Systems, 8(01), 87-116.

Koomen, R., \& Herrmann, E. (2018). An investigation of children's strategies for overcoming the tragedy of the commons. Nature Human Behaviour, 2(5), 348. 
LoBue, V., Nishida, T., Chiong, C., DeLoache, J. S., \& Haidt, J. (2011). When getting something good is bad: Even three-year-olds react to inequality. Social Development, 20(1), 154170.

Marquart, J. W. (1986). Prison guards and the use of physical coercion as a mechanism of prisoner control. Criminology, 24(2), 347-366.

McAuliffe, K., Blake, P. R., Kim, G., Wrangham, R. W., \& Warneken, F. (2013). Social influences on inequity aversion in children. PLoS One, 8(12), e80966.

Melis, A. P., Grocke, P., Kalbitz, J., \& Tomasello, M. (2016). One for you, one for me: Humans' unique turn-taking skills. Psychological Science, 27(7), 987-996.

Paulsen, D., Platt, M., Huettel, S. A., \& Brannon, E. M. (2011). Decision-making under risk in children, adolescents, and young adults. Frontiers in Psychology, 2, 72.

Raijmakers, M. E. J., Mandell, D. J., van Es, S. E., \& Counihan, M. (2014). Children's strategy use when playing strategic games. Synthese, 191(3), 355-370.

Sánchez-Amaro, A., Duguid, S., Call, J., \& Tomasello, M. (2017). Chimpanzees, bonobos and children successfully coordinate in conflict situations. Proceedings of the Royal Society B: Biological Sciences, 284(1856), 20170259.

Sánchez-Amaro, A., Duguid, S., Call, J., \& Tomasello, M. (2018a). Chimpanzees' understanding of social leverage. PloS One, 13(12), e0207868.

Sánchez-Amaro, A., Duguid, S., Call, J., \& Tomasello, M. (2018b). Chimpanzees and children avoid mutual defection in a social dilemma. Evolution and Human Behavior.

Sánchez-Amaro, A., Duguid, S., Call, J., \& Tomasello, M. (2019). Chimpanzees and children avoid mutual defection in a social dilemma. Evolution and Human Behavior, 40(1), 46-54.

Sugden, R. (2004). The economics of rights, co-operation and welfare. Springer. 
698

699

700

701

702

703

704

705

706

707

708

709

710

711

712

713

714

715

716

717

718

719

14

\section{5}

Therneau, T. (2012). coxme: mixed effects Cox models. R package version 2.2-3. Vienna, Austria: R Foundation for Statistical Computing.

Ulber, J., Hamann, K., \& Tomasello, M. (2015). How 18-and 24-month-old peers divide resources among themselves. Journal of Experimental Child Psychology, 140, 228-244.

Warneken, F. (2018). How children solve the two challenges of cooperation. Annual Review of Psychology, 69.

Warneken, F., Lohse, K., Melis, A. P., \& Tomasello, M. (2011). Young children share the spoils after collaboration. Psychological Science, 22(2), 267-273.

Warneken, F., Steinwender, J., Hamann, K., \& Tomasello, M. (2014). Young children's planning in a collaborative problem-solving task. Cognitive Development, 31, 48-58.

Wyman, E., Rakoczy, H., \& Tomasello, M. (2013). Non-verbal communication enables children's coordination in a "Stag Hunt" game. European Journal of Developmental Psychology, 10(5), 597-610.

(1)

2

13


Model 1: Subjects' choices

Model 1 investigated whether subjects would strategically use the leverage for their own benefit. We hypothesize that if subjects would understand the potential use of the leverage baited on the alternative platform, we would find a leverage effect in the direction of subjects accessing more often their leverage the bigger it was. The full model included the test variable leverage level (3-level factor) I and the control variables trial, session (which also accounts for role order) and sex of the pair as fixed effects; pair, individual on the right side and individual on the left side as random effects and the random slopes. The comparison between the full and the null model was significant (GLMM: $\chi^{2}=74.36, \mathrm{df}=3, p<0.001, \mathrm{~N}=240$ ). We found a main effect of leverage (see Table S1). Children accessed their leverage most of times when that consisted of four rewards, and almost never when no leverage was available.

Table S1: Model 1 information

\begin{tabular}{|c|c|c|c|c|c|c|}
\hline Term & Estimate & $\begin{array}{l}\text { Standard } \\
\text { Error }\end{array}$ & $\begin{array}{l}\text { Chi- } \\
\text { square }\end{array}$ & $\begin{array}{l}\text { Degrees of } \\
\text { freedom }\end{array}$ & $\begin{array}{l}\mathrm{p}- \\
\text { value }\end{array}$ & $\begin{array}{l}\mathrm{Cl}(95 \%) \text { of } \\
\text { the model }\end{array}$ \\
\hline Intercept & -2.79 & 0.56 & - & - & - & $-27.24,1.35$ \\
\hline $\begin{array}{l}\text { Leverage } \\
\text { (lev. 2) }\end{array}$ & 3.14 & 0.57 & 68.42 & 2 & $<0.001$ & $1.77,31.39$ \\
\hline $\begin{array}{l}\text { Leverage } \\
\text { (lev. 4) }\end{array}$ & 6.26 & 0.79 & 68.42 & 2 & $<0.001$ & $4.6,58.53$ \\
\hline Session & 0.57 & 0.23 & 6.43 & 1 & 0.01 & $-0.08,6.09$ \\
\hline Trial & -0.0 .6 & 0.23 & 0.07 & 1 & 0.79 & $-1.4,0.79$ \\
\hline
\end{tabular}




\begin{tabular}{|l|l|l|l|l|l|l|}
\hline Dyad sex & 0.15 & 0.56 & 0.07 & 1 & 0.79 & $-1.99,2.77$ \\
(male) & & & & & \\
\hline
\end{tabular}

735

Model 2. Subjects latency to access the apparatus.

737 Model 2 investigated subjects' latencies to access the apparatus. We hypothesized that, if

738 subjects would understand the potential use of the leverage baited on the alternative platform,

739 they would wait longer to access the apparatus when the alternative platform consisted of zero or two glass marbles instead of four. For this model we established a censor to account for trials in which subjects did not open the door after 15 seconds and for trials in which partners pulled from their rope before subjects acted. The censored data represented $17 \%$ of the total data ( 40 of 240 trials). The model included the test variable level of leverage and the control variables trial, session (which also accounts for role order) and sex of the pair as fixed effect. Individual identity was introduced as a random effect. The leverage level was significant (coxme, $\chi^{2}=26.59$, df $=2, p<0.001, N=240$ ). Subjects waited longer to open the sliding door the smaller the

747 leverage was (see Table S2).

Table S2: Model 2 information

\begin{tabular}{|l|l|l|l|l|l|}
\hline Term & Model & Standard & HR (Hazard & p- & Cl of model \\
2) & coefficients & error & Ratios) & value & estimates \\
\hline Leverage (lev. & 0.15 & 0.18 & 1.16 & 0.4 & $-0.36,0.41$ \\
\hline Leverage (lev. & 0.92 & 0.19 & 2.49 & $<0.001$ & $-0.36,0.38$ \\
\hline Dyad_sex & 0.64 & 0.19 & 1.89 & $<0.001$ & $-0.41,0.42$ \\
(male) & & & & & \\
\hline
\end{tabular}




\begin{tabular}{|l|l|l|l|l|l|}
\hline Session & 0.08 & 0.19 & 1.09 & 0.66 & $-0.39,0.41$ \\
\hline Trial & 0.08 & 0.04 & 1.09 & 0.054 & $0.04,0.08$ \\
\hline
\end{tabular}

749

Figure S1: Subjects' latency to access the apparatus as a function of the leverage level presented

751 to the subject. The higher the level of leverage the faster the subject accessed the apparatus.

752 The horizontal lines represent the average latencies. The blank dots represent the censored 753 data: trials in which subjects did not open the access after 15 seconds and trials in which partners 754 pulled their rope before subjects acted.

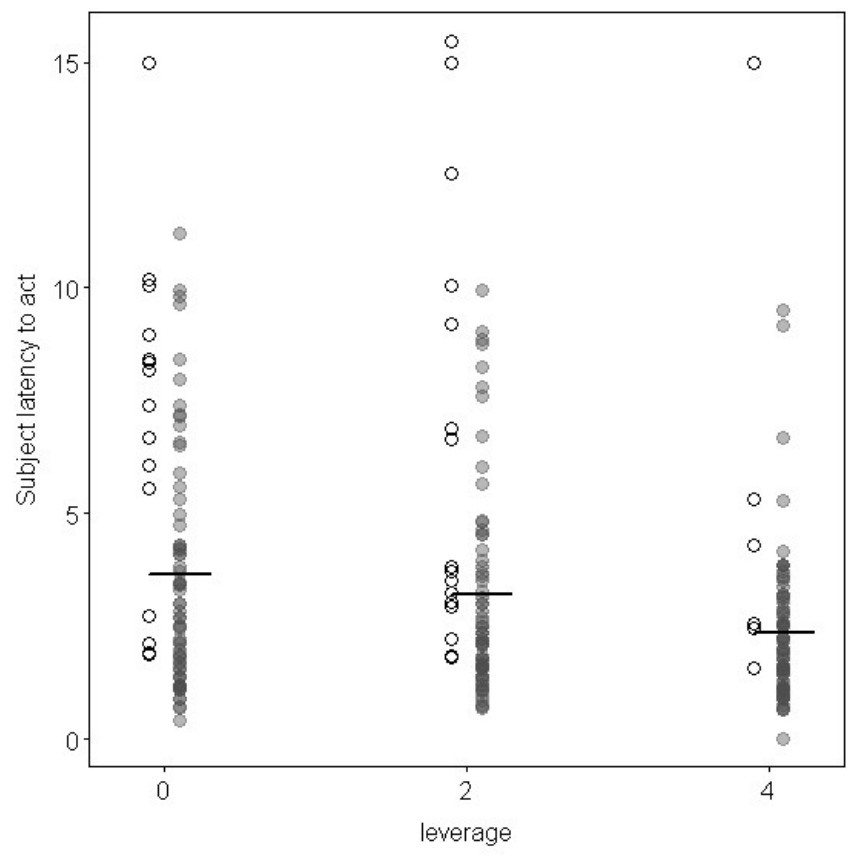

755

757 Model 3. Partners' latency to pull from the rotating tray.

758 Model 3 investigated partners' latencies to pull from their rotating tray. We hypothesized that,

759 if partners would understand the role of subjects' leverage, they would tend to pull faster the

760 larger the subjects' leverage was-as the subjects would likely access its own alternative when

761 this one consisted of four glass marbles. For this model we established a censor to account for

762 trials in which the partner did not open the door after 15 seconds and for trials in which either 
the subject opened their access to the leverage before the partners had pulled, or the subjects pulled before the partners. In other words, when partners had no chances to freely decide whether to pull or wait for subjects to act. The censored data represented $77 \%$ of the total data (185 of 240 trials). The model included the test variable level of leverage and the control variables trial, session (which also accounts for role order) and sex of the pair as fixed effect. Individual identity was introduced as random effect. The level of leverage was significant (coxme, $\chi^{2}=8.84, \mathrm{df}=2, p=0.010, \mathrm{~N}=240$ ). Partners waited longer to open the sliding door the smaller the leverage of the subject was (see Table S3). In other words, partners waited longer to act when both had similar chances to obtain the highest reward baited on the free end of the rotating tray.

Table S3: Model 3 information

\begin{tabular}{|l|l|l|l|l|l|}
\hline Term & Model & Standard & HR (Hazard & Cl of model \\
& coefficients & error & Ratios) & estue & \\
\hline Leverage (lev. 2) & -0.06 & 0.29 & 0.94 & 0.84 & $-0.65,0.69$ \\
\hline Leverage (lev. 4) & -1.2 & 0.47 & 0.3 & 0.01 & $-0.61,0.72$ \\
\hline Dyad_sex (male) & -0.58 & 0.37 & 0.56 & 0.12 & $-0.74,0.73$ \\
\hline Session & -0.51 & 0.37 & 0.6 & 0.17 & $-0.69,0.71$ \\
\hline Trial & 0.12 & 0.08 & 1.12 & 0.16 & $0.13,0.2$ \\
\hline
\end{tabular}

774

Figure S2: Partners' latency to access the apparatus as a function of the leverage level presented to the subject. The higher the level of leverage the faster the partner accessed the apparatus.

777 The horizontal lines represent the average latencies. The blank dots represents' the censored data: trials in which partners did not open the access after 15 seconds and trials in which subjects pulled their rope before partners acted. 


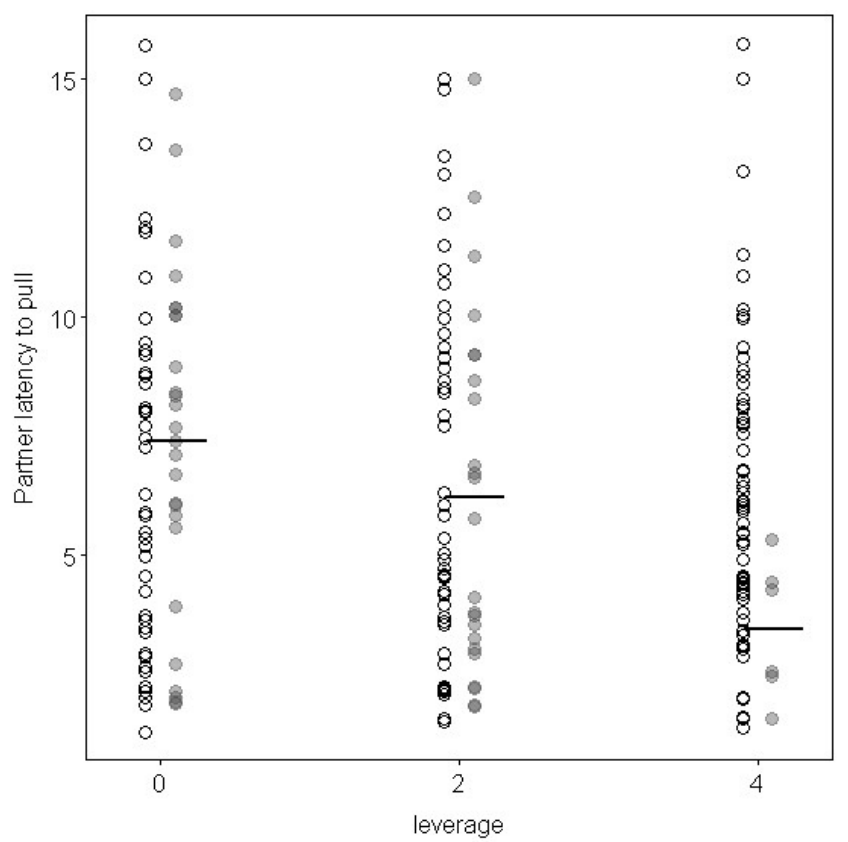

781

782

Model 4. Communication

783

784

Model 4 investigated the occurrence of communication. In this model we included all trials. We transformed our response into a binomial response where 1 meant the presence of any communicative act for subjects and partners and 0 no presence of communication within a trial. The full model included the communicator ID (subject or partner), the leverage phase and the trial phase (trial and inter-trial-intervals) as well as the two-way interaction between communicator ID and leverage phase. We expected children to communicate more during interacting phases. In addition, we expected partners without leverage to communicate more than subjects when the latter had access to alternative rewards. The control variables were trial, session and sex of the dyad as fixed effects; pair and trial ID as random effects and all possible random slopes. The comparison between the full and the null model excluding all test variables was not significant (GLMM: $\chi^{2}=5.73, \mathrm{df}=6, p=0.45, \mathrm{~N}=960$ ). In addition, we tested a model only including informative communicative acts (the most represented form of communication). The comparison between the full and the null model excluding test variables was not significant (GLMM: $\chi^{2}=5.49, \mathrm{df}=6, p=0.48, \mathrm{~N}=960$ ). 
798 Table S4. Number of times each communicative type occurred per leverage level, child role and 799 trial phase (maximum value per cell $=80$ ).

\begin{tabular}{|c|c|c|c|c|c|c|}
\hline & Phase 1 & & & & & \\
\hline & Subject & & & Partner & & \\
\hline & Leverage & Leverage & Leverage & Leverage & Leverage & Leverage \\
\hline & 0 & 2 & 4 & 0 & 2 & 4 \\
\hline Informative & 37 & 32 & 32 & 35 & 34 & 35 \\
\hline Imperative & 22 & 7 & 1 & 16 & 5 & 6 \\
\hline Protest & 10 & 7 & 5 & 14 & 12 & 6 \\
\hline Leverage & 4 & 2 & 1 & 2 & 1 & 1 \\
\hline Turn taking & 8 & 5 & 1 & 6 & 4 & 2 \\
\hline \multirow[t]{5}{*}{ Others } & 22 & 26 & 19 & 24 & 20 & 15 \\
\hline & Phase 2 & & & & & \\
\hline & Subject & & & Partner & & \\
\hline & Leverage & Leverage & Leverage & Leverage & Leverage & Leverage \\
\hline & 0 & 2 & 4 & 0 & 2 & 4 \\
\hline Informative & 37 & 39 & 39 & 43 & 35 & 39 \\
\hline Imperative & 3 & 1 & 1 & 3 & 1 & 0 \\
\hline Protest & 5 & 1 & 0 & 3 & 4 & 7 \\
\hline Leverage & 1 & 5 & 1 & 1 & 1 & 2 \\
\hline Turn taking & 3 & 1 & 0 & 1 & 2 & 1 \\
\hline Others & 14 & 15 & 18 & 14 & 16 & 9 \\
\hline
\end{tabular}

800 